\title{
New Gel Polyelectrolytes for Rechargeable Lithium Batteries
}

\author{
Xiao-Guang Sun, Gao Liu, Jiangbing Xie, Yongbong Han, John B. Kerr* \\ Lawrence Berkeley National Laboratory, MS 62-203, \\ One Cyclotron Road, Berkeley, CA 94720
}

\begin{abstract}
New polyelectrolytes were synthesized by grafting the allyl group containing lithium salt, lithium bis(allylmalonato) borate (LiBAMB), onto poly[poly(ethylene glycol) methyl ether acrylate-co-allyoxyethyl acrylate] through hydrosilylation chemistry. Gel polyelectrolytes were obtained by adding $50 \mathrm{wt} \%$ of different $1 / 1(\mathrm{wt} / \mathrm{wt})$ mixtures of propylene carbonate (PC), ethylene carbonate (EC), dimethyl carbonate (DMC) and tetraethyleneglycol dimethyl ether (TEGDME). The highest ambient conductivity was $2.7 \times 10^{-8}{\mathrm{~S} . \mathrm{cm}^{-1}}$ for the dry single ion conductors and $7.9 \times 10^{-6}{\mathrm{~S} . \mathrm{cm}^{-1}}^{-1}$ for the gel single ion conductor containing $50 \mathrm{wt} \%$ of EC/DMC $(1 / 1, w t / w t)$ and both are obtained for the sample with an EO/Li ratio of 40:1. The conductivity order of gel electrolytes containing the same amount of different mixed solvents suggests that the conductivity of the gel is more determined by the dielectric constant rather than by the viscosity of the solvent. The preliminary $\mathrm{Li} / \mathrm{Li}$ cycling profile of a dry single ion conductor is encouraging, as almost no concentration polarization and relaxation was observed. However, some fluctuation of potential occurred, which might be due to the reactions of the electrolyte on the surface of lithium metal.
\end{abstract}

Keywords: Single ion conductors, ionic conductivity, plasticizer, gel electrolytes, cell cycling

\footnotetext{
* Corresponding author: jbkerr@lbl.gov
} 


\section{Introduction}

System modeling results have shown that in applications such as electric vehicles, where a high discharge rate is desired, electrolytes with a $\mathrm{Li}^{+}$ion transference number equal to unity can substantially improve active material utilization [1]. As a result interest is growing in the synthesis and characterization of new single ion conductors. Most single ion conductors are synthesized by fixing either alkyl sulfonate [2] or carboxylate [3] to the polymer backbones. However, due to the limited solubility and ion dissociation in polyether media, the ambient

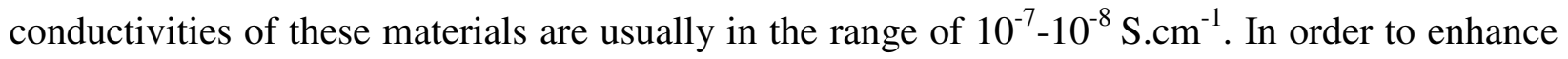
the ionic dissociation, different anions have been synthesized [4, 5] and ambient conductivities of $10^{-6}-10^{-7} \mathrm{~S} . \mathrm{cm}^{-1}$ have been realized. Shriver and coworkers [6] reported ambient conductivity of $10^{-5} \mathrm{~S}_{\mathrm{cm}}{ }^{-1}$ for lithium conductive poly (aluminosilicate). In addition, plasticizers have

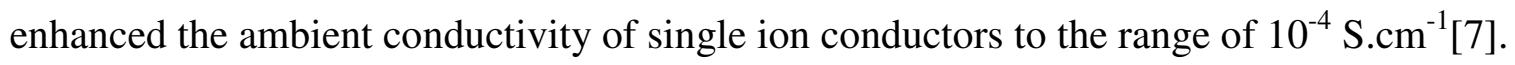

In this paper we report the synthesis of a new kind of single ion conductor based on a new lithium salt, lithium bis(allylmalonato)borate (LiBAMB), and an allyl group containing comb branch polyacrylate ether (Scheme 1). Since LiBAMB has allyl groups on both sides, after connection to the polymer chain through tetramethyldisiloxane by hydrosilylation it not only acts as a lithium source but also acts as a cross-linking site to enhance the mechanical properties of the resulting new single ion conductors. Plasticizers such as mixtures of PC, EC, DMC and TEGDME were used to obtain the corresponding gel single ion conductors.

\section{Experimental}

The synthesis of LiBAMB, shown in Scheme 1, follows the literature procedure $[8,9]$. The structures of the synthesized monomers, prepolymers as well as the final single ion conductors were confirmed by NMR and full details will be given elsewhere [10]. Glass 
transition temperatures $\left(\mathrm{T}_{\mathrm{g}}\right)$ were measured using a Perkin Elmer-7 DSC instrument. The heating rate was kept at $10^{\circ} \mathrm{C} / \mathrm{min}$. The $\mathrm{T}_{\mathrm{g}}$ is defined as the heat capacity jump onset temperature. The melting temperature $\mathrm{T}_{\mathrm{m}}$ was obtained from the peak temperature of the melting process. The measurement of transport properties was carried out according to the method of Newman and coworkers [11,12]. Conductivity measurements AC impedance were made with blocking stainless steel electrodes in Swagelok cells $\mathrm{Li} / \mathrm{Li}$ cells were constructed inside a Helium filled dry box and the cells were cycled at $85^{\circ} \mathrm{C}$ at different current densities.

\section{Results and Discussion}

The general physical properties of the prepolymers, the dry single ion conductors as well as those of the gel single ion conductors are summarized in Table 1. For prepolymers with increasing the content of crosslinker (lower $\mathrm{x}$ value), 2-allyoxyethyl acrylate, the molecular weight increases and the corresponding glass transition temperature also increases. After crosslinking by LiBAMB through hydrosilylation, the glass transition temperatures of the resulting dry single ion conductors are all higher than those of the corresponding prepolymers. Here the increase of glass transition temperature is not only due to the crosslinking by the bridging lithium salt but also due to the complexation of lithium cation by carboxylate group in the anion and oligoether side chains. As expected after plasticizing with $50 \mathrm{wt} \%$ EC/DMC $(1 / 1, w t / w t)$, all the glass transition temperatures of the gel single ion conductors are lower than those of the corresponding dry single ion conductors by at least $20^{\circ} \mathrm{C}$.

The ionic conductivities of dry single ion conductors shown in Fig. 1 are disappointedly low, which are mainly due to the severe ion pairing effect between the lithium ion and the BMB anion. The highest ambient conductivity of $2.7 \times 10^{-8}{\mathrm{~S} . \mathrm{cm}^{-1}}$ is obtained for the sample with an $\mathrm{EO} / \mathrm{Li}$ of $40 / 1$. The maximum in conductivity is due to the trade off in the effects of chain 
flexibility versus charge carrier concentration. Higher charge carrier concentration results in more lithium ions moving but also restricts the motion of the polymer chains due to ionic crosslinking which results in an increase in the $T_{g}$ and lower mobility. This effect apparently extends to the gel systems also. The addition of $50-\mathrm{wt} \% \mathrm{EC} / \mathrm{DMC}(1 / 1, \mathrm{wt} / \mathrm{wt})$ to the dry single ion conductors not only increases mobility of the salt but also is likely to dissociate more ion pairs into free ions. These combined effects result in an increase of more than two orders of magnitude higher conductivity of the resulting gel single ion conductor over the corresponding dry single ion conductor. Raman and FT-IR spectroscopy is presently being applied to investigate the extent of ion dissociation. The highest ambient conductivity of $7.9 \times 10^{-6}{\mathrm{~S} . \mathrm{cm}^{-1}}^{-1}$ for gel single ion conductor is obtained for the same sample with $\mathrm{EO} / \mathrm{Li}$ ratio of 40/1.

Fig. 2 shows the solvent effect on ionic conductivities of gel single ion conductors that were formed from the same dry sample, $\mathrm{EO} / \mathrm{Li}=10$, and $50 \mathrm{wt} \%$ of a variety of solvents mixed in 1/1 (wt/wt) ratio. For the mixture of PC/EC that has the highest dielectric constant and highest viscosity, the corresponding gel shows the highest conductivity. For the mixture of DMC/TEGDME that has the lowest dielectric constant and medium viscosity, the corresponding gel shows the lowest conductivity. In the middle, the mixture of EC/DMC has a similar viscosity to that of PC/DMC and the mixture of EC/TEGDME has similar viscosity as that of PC/TEGDME. However, the gels containing the EC mixture show higher conductivity than those containing the PC mixture. In addition, the TEGDME containing mixtures such as EC/TEGDME and PC/TEGDME have higher viscosity and higher dielectric constant than DMC containing mixtures such as EC/DMC and PC/DMC but the gels containing TEGDME mixture show higher conductivity than those gels containing DMC mixture. These observations seem to 
induicate that for gel single ion conductors the conductivity is more determined by the dielectric constant rather than by the viscosity of the solvent.

The dry single ion conductor with a salt concentration of $\mathrm{EO} / \mathrm{Li}=80 / 1$ was used to construct a $\mathrm{Li} / \mathrm{Li}$ cell, which was cycled under the sequence of $1 \mathrm{hr}$ relaxation, $2 \mathrm{hr}$ charge, $1 \mathrm{hr}$ relaxation, $2 \mathrm{hr}$ discharge at a current density of $50 \mu \mathrm{A} . \mathrm{cm}^{-2}$. The preliminary result shown in Fig.3 is encouraging, since as expected for single ion conductors, almost no concentration polarization and relaxation was observed. It can be observed that the application of the current results in an immediate polarization of the voltage which then decreases with further current. Concentration polarization would result in a further increase in voltage after the immediate instantaneous polarization. The relatively high initial potential is caused by large bulk and interfacial impedances (not shown here). The gradual increase of potential with cycling is due to the increase of interfacial impedance, which is apparently related to the buildup of the SEI layer. The potential fluctuation within one cycle might be related to some undesired reactions on the surface of lithium metal, since trace amount of one end free silane from uncompleted crosslinking steps might still present in the electrolytes and the hydrogen in the methide group between the two carbonyls of the salt is also more active. These are all susceptible to attack by lithium metal at a temperature as high as $85^{\circ} \mathrm{C}$. Further studies are underway to elucidate the mechanism in more detail.

Acknowledgements: Financial support of this work from NASA is acknowledged.

\section{References:}

1. M. Doyle, T. F. Fuller, J. Newman, Electrochim. Acta, 39, 2073 (1994).

2. Y. Ito, H. Ohno, Solid State Ionics, 79, 300 (1995). 
3. N. Kobayashi, M. Uchiyama, E.Tsuchida, Solid State Ionics, 17, 307(1985).

4. D, Benrabah, S. Sylla, F. Alloin, J.Y.Sanchez, M. Armand, Electrochimica Acta, 40(13\&14), 2259(1995).

5. K. Onishi, M.Matsumoto, M. Nakacho, K.Shigehara, Chem. Mater., 8, 469(1996).

6. T. Fujinami, A.Tokimune, M.A.Mehta, D.F.Shriver, G.C.Rawsky, Chem. Mate, 9, 2236 (1997).

7. S.H.Chung, P.Heitjans, R.Winter, W.Bzaucha, Florjanczyk, Y.Onoda, Solid State Ionics, 112, 153 (1998).

8. W. Xu, C.A. Angell, Electrochem. Solid-State Lett., 4, E1 (2001).

9. U. Lishka, U. Wietelmann, M. Wegner, German Pat. DE19829030 C1 (1999)

10. X. G. Sun, C. Reeder, J. B. Xie, J. B. Kerr, Macromolecues, in preparation.

11. Y. P.Ma, M. Doyle, T.F. Fuller, M.M.Doeff, L.C.De Jonghe, J.Newman, J. Electrochem. Soc., 142, 1859 (1995).

12. M.M.Doeff, L.Edman, S.E.Sloop, J.Kerr, L.C.De Jonghe, J.Power Sources, 89, 227(2000). 


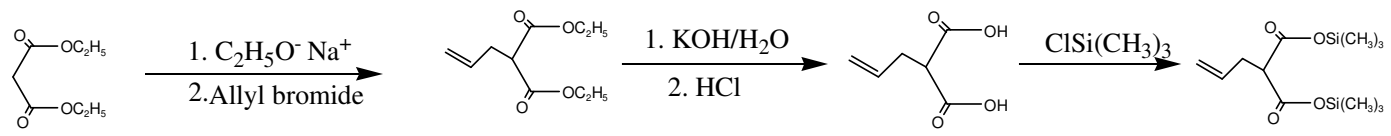
$\mathrm{CH}_{3} \mathrm{CH}_{3}$

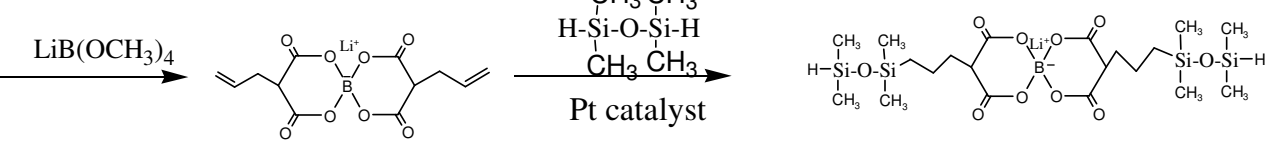

LiBAMB

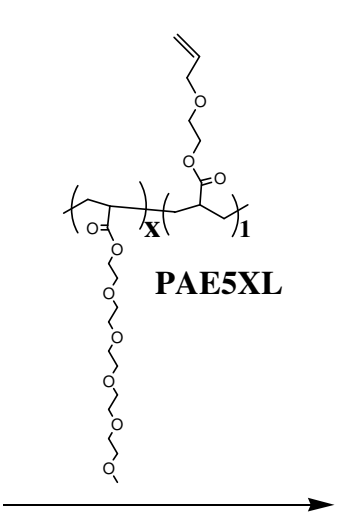

$\mathrm{P}_{\mathrm{t}}$ Catalyst

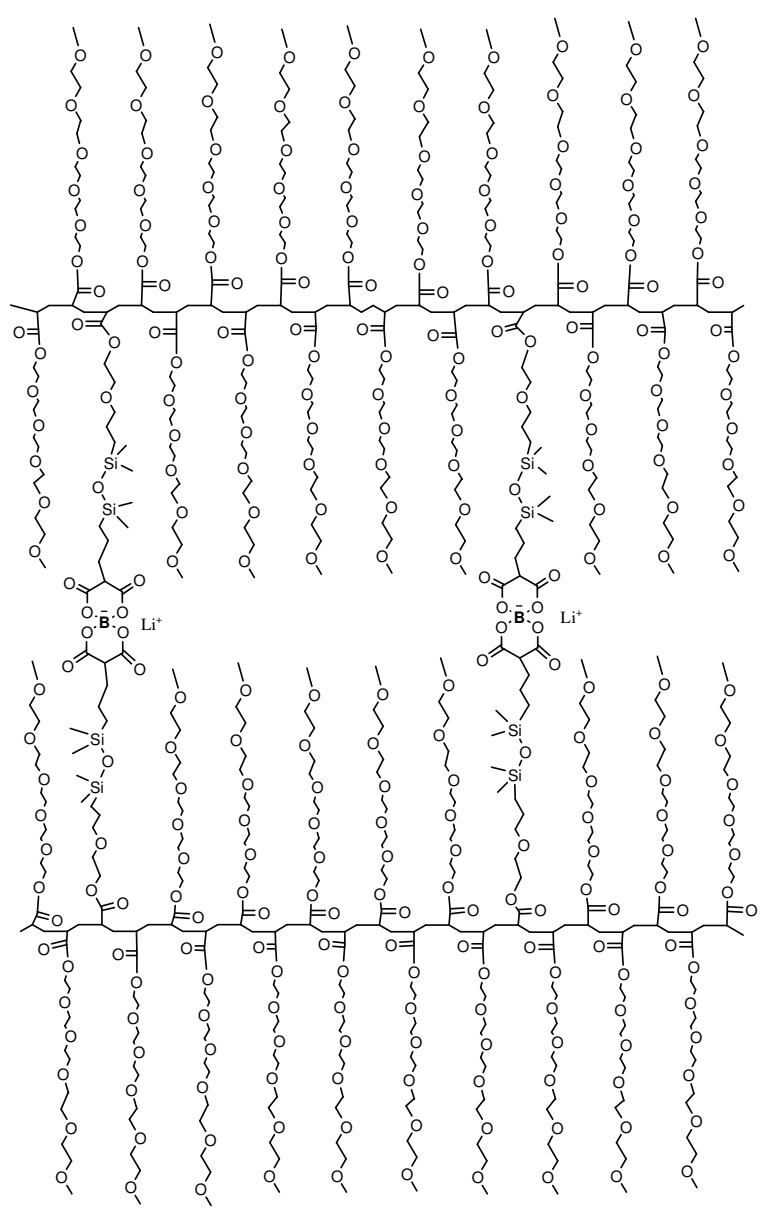

Scheme1: Synthesis of network type single ion conductors 
Table 1. Summary of physical properties of prepolymers, dry single ion conductors and gel single ion conductors.

\begin{tabular}{|c|c|c|c|c|c|}
\hline \multicolumn{2}{|c|}{} & I & II & III & IV \\
\hline \multirow{4}{*}{\begin{tabular}{c} 
Prepolymers \\
\cline { 2 - 6 }
\end{tabular}} & $\mathrm{Mw}\left(\mathrm{x} 10^{4}\right)$ & 11.7 & 3.12 & 2.20 & 1.48 \\
\cline { 2 - 6 } & $\mathrm{PDI}$ & 1.78 & 2.31 & 1.88 & 1.59 \\
\cline { 2 - 6 } & $\mathrm{T}_{\mathrm{g}} /{ }^{\circ} \mathrm{C}$ & -44.8 & -59.5 & -63.0 & -64.7 \\
\hline \multirow{3}{*}{$\begin{array}{c}\text { Ion Conductors } \\
\text { Dry single }\end{array}$} & $\mathrm{EO} / \mathrm{Li}$ & $10 / 1$ & $20 / 1$ & $40 / 1$ & $80 / 1$ \\
\cline { 2 - 6 } & $\mathrm{T}_{\mathrm{g}} /{ }^{\circ} \mathrm{C}$ & -37.2 & -52.5 & -54.7 & -55.4 \\
\cline { 2 - 6 } & $\mathrm{Log} \sigma_{25}$ & ---- & -7.94 & -7.57 & -7.96 \\
\hline \multirow{3}{*}{$\begin{array}{c}\text { Gel Single Ion Conductors } \\
\text { with 50 wt\% }\end{array}$} & $\mathrm{EO} / \mathrm{Li}$ & $10 / 1$ & $20 / 1$ & $40 / 1$ & $80 / 1$ \\
\cline { 2 - 6 } EC/DMC (1/1, by wt) & $\mathrm{T}_{\mathrm{m}}{ }^{\circ} \mathrm{C}$ & 35.1 & 24.1 & $-21.8 ; 5.9$ & $-18.8 ; 17.1$ \\
\cline { 2 - 6 } & $\mathrm{T}_{\mathrm{g}} /{ }^{\circ} \mathrm{C}$ & -58.2 & -74.0 & -80.4 & -86.1 \\
\cline { 2 - 6 } & $\mathrm{Log}_{25}$ & -5.97 & -5.27 & -5.10 & -5.51 \\
\hline
\end{tabular}

Note: DSC scan of EC/DMC (1/1, wt/wt) shows two large peaks at -16 and $16^{\circ} \mathrm{C}$ and the two small melting peaks of pure $\mathrm{DMC}$ and $\mathrm{EC}$ at around $0^{\circ} \mathrm{C}$ and $36^{\circ} \mathrm{C}$ respectively. 


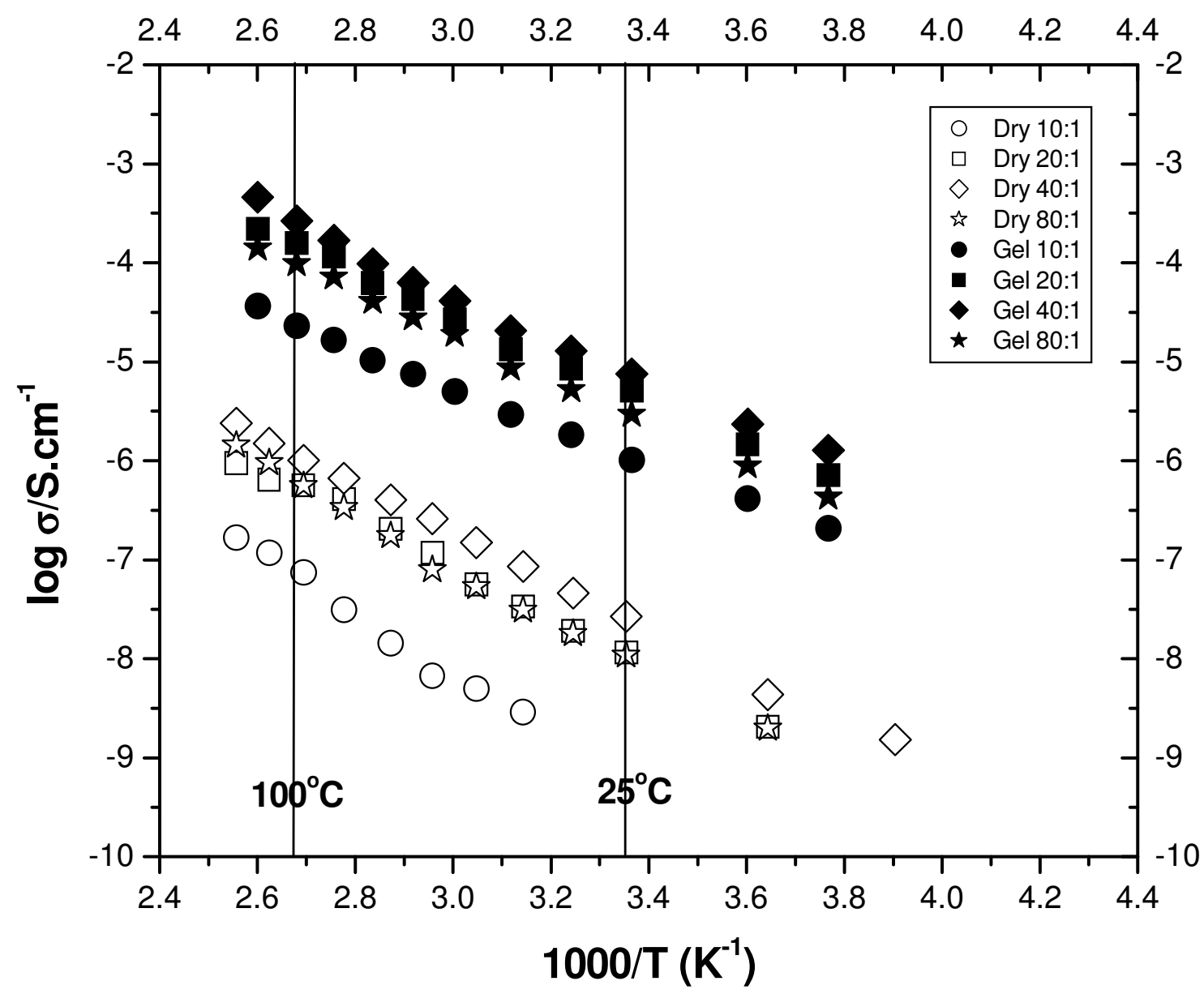

Fig. 1. Arrhenius plots of ionic conductivities of dry single ion conductors and those of gel single ion conductors containing $50 \mathrm{wt} \%$ of EC/DMC (1/1, wt/wt). 


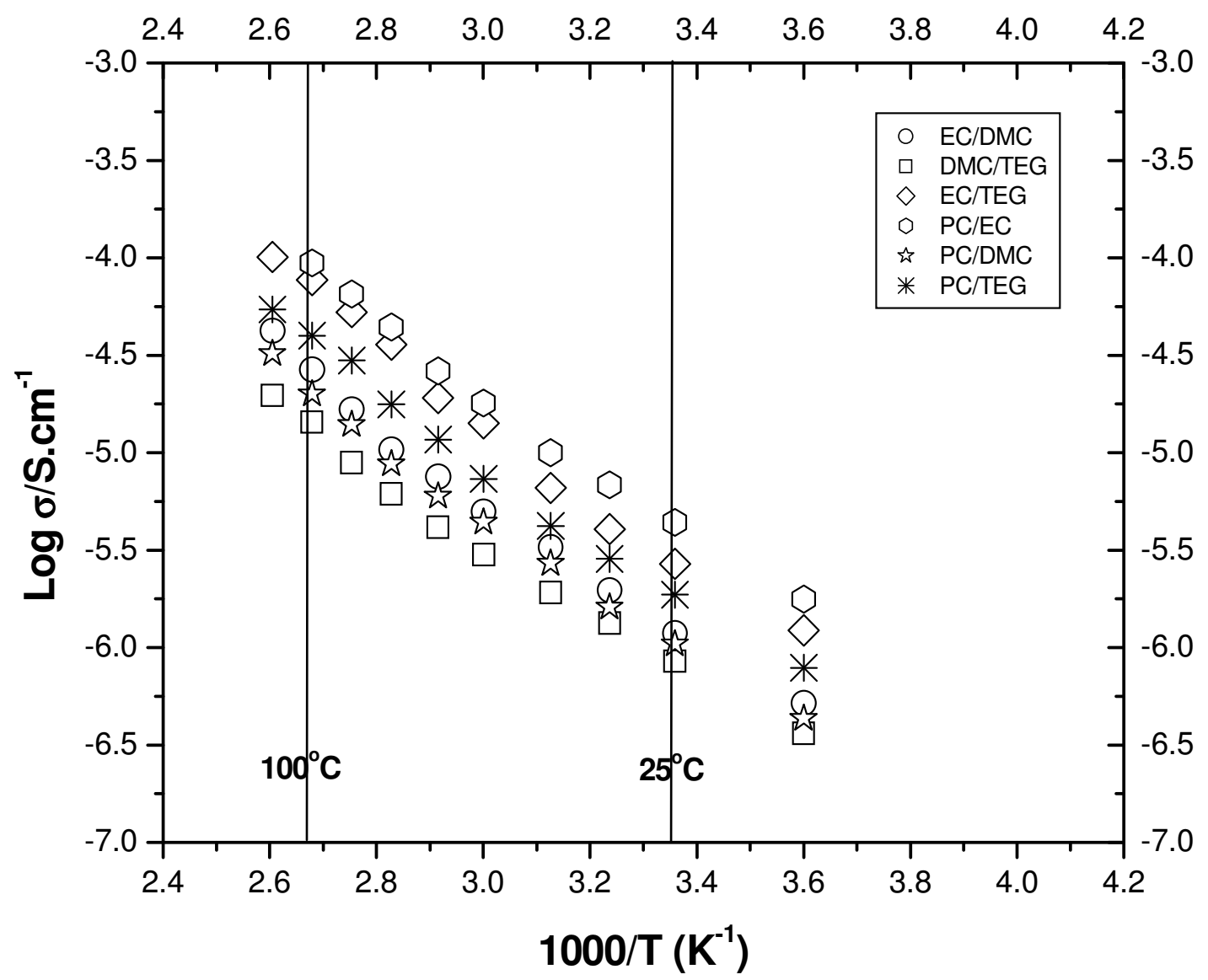

Fig. 2. Arrhenius plots of ionic conductivities of the dry single ion conductor with salt content of $\mathrm{EO} / \mathrm{Li}=10$ containing $50 \mathrm{wt} \%$ of different mixed plasticizers $(1 / 1, \mathrm{wt} / \mathrm{wt})$. 


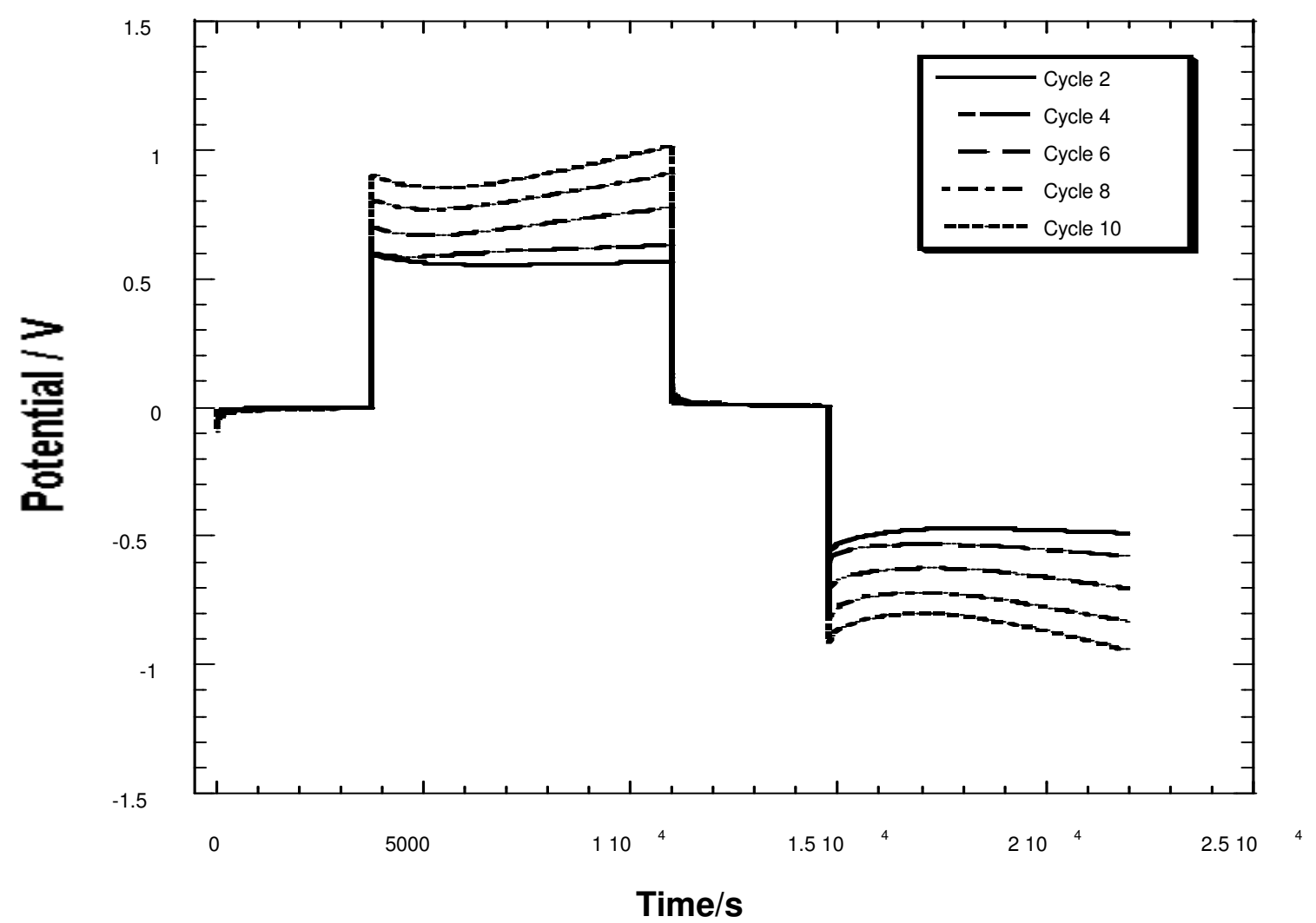

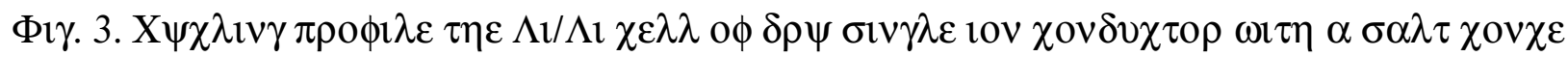

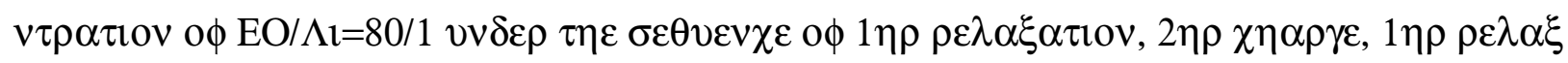

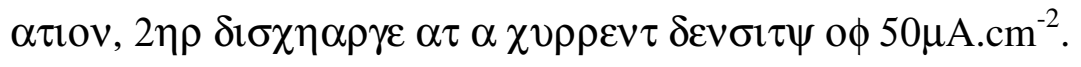

